\title{
Sleep Duration and Obesity
}

\author{
JungHwan Kim* \\ Department of Family Medicine, Eulji Hospital, Eulji University, College of Medicine, Seoul, Korea
}

\author{
*Corresponding author \\ JungHwan Kim \\ http://orcid.org/0000-0001-8984-2914 \\ Department of Family Medicine, Eulji \\ Hospital, Eulji University, College of \\ Medicine, 68 Hangeulbiseok-ro, Nowon- \\ gu, Seoul 01830, Korea \\ Tel: +82-2-970-8515 \\ Fax: +82-2-970-8370 \\ E-mail: twthrib@eulji.ac.kr
}

Sleep has an important role in promoting the normal activities and health of the body. Recent studies have shown that lack of sleep quality and sleep time lead to various health changes. In particular, research has shown that sleep time is related to the incidence of cardiovascular disease and mortality. ${ }^{1}$ In addition, a difference in the incidence of obesity according to sleeping time was reported. ${ }^{2-8}$ In other words, if the appropriate sleep time is not achieved, the rate of obesity increases. Epidemiologic studies of sleep and obesity in many countries have shown a similar pattern of decrease in sleep time and increase in obesity. According to a US survey, the proportion of people sleeping more than the recommended 8 hours decreased from $38 \%$ in 2001 to $26 \%$ in $2005 .{ }^{3}$ In Korea, the percentage of people who sleep more than 6 hours a day increased from $15.6 \%$ in the 1960 s to $38.6 \%$ in 2001 , while the percentage of people reporting 7-8 hours of sleep decreased from $58.8 \%$ in 1998 to $52 \%$ in $2001 .^{6}$ In most studies, 7-8 hours of sleep seems to be associated with the smallest proportion of obesity. In Korea, the results of the National Health and Nutrition Examination Survey conducted from 2001 to 2005 showed that the relative risk of obesity was $24 \%$ when sleep time was less than 5 hours. The risk of developing abdominal obesity was reported to increase by $22 \%{ }^{6}$ It is also known that short sleep time increases the incidence of type 2 diabetes and metabolic syndrome., ${ }^{2,9-11}$ The relationship between sleeping time and obesity by age has not been studied much, but the relationship between short sleep time and obesity seems to be clearer at a young age. ${ }^{8}$

The mechanism by which short sleep time induces obesity is not yet clear, but various hypotheses are being established. ${ }^{4}$ Short sleep time is known to be highly involved in appetite control. In particular, it increases the secretion of ghrelin, which induces an increase in appetite and inhibits the secretion of leptin, which helps suppress appetite. ${ }^{2,5}$ This means that the shorter is the sleep time, the greater is the feeling of hunger, thereby increasing the food intake. Sleep deprivation also tends to induce sympathetic nervous system activity, increase secretion of cortisol, and increase secretion of growth hormone (GH) at night.,10,12 This may lead to insulin resistance and problems with blood glucose control. This process is thought to lead to the development of type 2 diabetes and metabolic syndrome. It is known that, in a normal sleeping process, a change in blood glucose control occurs in order to keep blood sugar constant. During non-REM sleep, the use of blood sugar is lowest; that during REM sleep is highest, while blood glucose level is lowest. However, as sleep time decreases, there is a change in the mechanism of blood glucose control during sleep, and this change may increase the likelihood of glucose control abnormality. In addition, the increase in appetite due to short sleep duration causes an increase of visceral fat and insulin resistance, which can affect the development of diabetes and metabolic syndrome. Short sleep 
time causes excessive daytime sleepiness and naturally affects activity in everyday life. ${ }^{13}$ This leads to a reduction in intentional athletic activity, resulting in a reduction in overall energy expenditure. The relationship between quality of sleep and obesity is not yet clear. In some studies, researchers have reported that the lower is the satisfaction with sleep, the higher is the incidence of obesity-related metabolic syndrome. ${ }^{14,15}$ Ultimately, control of the duration and quality of sleep will be important in controlling the risk of obesity and metabolic diseases.

\section{CONFLICTS OF INTEREST}

There is no conflict of interest to declare.

\section{REFERENCES}

1. da Silva AA, de Mello RG, Schaan CW, Fuchs FD, Redline S, Fuchs SC. Sleep duration and mortality in the elderly: a systematic review with meta-analysis. BMJ Open 2016;6:e008119.

2. Knutson KL, Van Cauter E. Associations between sleep loss and increased risk of obesity and diabetes. Ann N Y Acad Sci 2008;1129:287-304.

3. Gangwisch JE, Malaspina D, Boden-Albala B, Heymsfield SB. Inadequate sleep as a risk factor for obesity: analyses of the NHANES I. Sleep 2005;28:1289-96.

4. Patel SR, Hu FB. Short sleep duration and weight gain: a systematic review. Obesity (Silver Spring) 2008;16:643-53.

5. Van Cauter E, Knutson KL. Sleep and the epidemic of obesity in children and adults. Eur J Endocrinol 2008;159 Suppl 1:S59-66.

6. Park SE, Kim HM, Kim DH, Kim J, Cha BS, Kim DJ. The as- sociation between sleep duration and general and abdominal obesity in Koreans: data from the Korean National Health and Nutrition Examination Survey, 2001 and 2005. Obesity (Silver Spring) 2009;17:767-71.

7. Ock SM, Ju SY, Choi WS, Park HM, Jung KI, Song CJ. Association of sleep hours with obesity in adult women. Korean J Obes 2008;17:110-6.

8. Jang SY, Ju EY, Park KM, Seo S, Choi SJ, Lee CK, et al. Association between sleep duration and obesity in young Korean adults. Korean J Obes 2016;25:207-14.

9. Knutson KL, Spiegel K, Penev P, Van Cauter E. The metabolic consequences of sleep deprivation. Sleep Med Rev 2007;11: 163-78.

10. Spiegel K, Knutson K, Leproult R, Tasali E, Van Cauter E. Sleep loss: a novel risk factor for insulin resistance and Type 2 diabetes. J Appl Physiol (1985) 2005;99:2008-19.

11.Ju SY, Choi WS. Sleep duration and metabolic syndrome in adult populations: a meta-analysis of observational studies. Nutr Diabetes 2013;3:e65.

12. Magee CA, Huang XF, Iverson DC, Caputi P. Examining the pathways linking chronic sleep restriction to obesity. J Obes 2010;2010:821710.

13. Atkinson G, Davenne D. Relationships between sleep, physical activity and human health. Physiol Behav 2007;90:229-35.

14. Logue EE, Scott ED, Palmieri PA, Dudley P. Sleep duration, quality, or stability and obesity in an urban family medicine center. J Clin Sleep Med 2014;10:177-82.

15. Hwang IC, Kim KK, Choi CH, Lee KS, Suh HS. Relationship between sleep duration, sleep satisfaction and metabolic syndrome. Korean J Health Promot 2010;10:71-7. 